\title{
DNMT1 genetic polymorphisms affect breast cancer risk in the central European Caucasian population
}

\author{
Kathrin Kullmann ${ }^{1}$, Mustafa Deryal ${ }^{2}$, Mei Fang Ong ${ }^{3}$, Werner Schmidt ${ }^{2}$ and Ulrich Mahlknecht ${ }^{1,4^{*}}$
}

\begin{abstract}
Introduction: DNA methylation of CpG islands within the promoter region of genes is an epigenetic modification with an important role in the development of cancer and it is typically mediated by DNA methyltransferases (DNMTs). In cancer cells, global hypomethylation of the genome as a whole and regional hypermethylation of CpG islands have been reported. Four groups of DNMTs have been identified: DNMT1, DNMT2 (TRDMT1), DNMT3A and DNMT3B. DNMT2 uses the catalytic mechanism of DNMTs, but does in fact methylate RNA. Little is known about the significance of these genes in human breast cancer. In the study presented herein, we analyzed five distinct DNMT single SNPs with regard to potential associations with breast cancer risk.
\end{abstract}

Case description: In this study, we genotyped 221 female Caucasian breast cancer patients and 221 female Caucasian healthy controls, and we used five allele-specific real-time polymerase chain reaction (qPCR) assays. We selected one locus within the DNMT1 gene and two loci within the DNMT3A and DNMT3B genes, respectively. Statistics were calculated using the chi-squared and Fisher's exact tests, and correlated with clinical parameters such as age, diagnosis, histology, TNM stage, hormonal receptor status, human epidermal growth factor receptor 2 (HER2) status, response to treatment and survival. Statistically significant results were obtained for correlations with the DNMT1 gene.

Discussion and Evaluation: Five genomic loci within the DNMT1, DNMT3A and DNMT3B genes were assessed. Statistical significance ( $P=0.030$ ) was identified for DNMT1 SNP (A201G, rs2228612): six women within the control group were GG homozygous (variant), while this mutation was absent in the breast cancer group.

Conclusions: We conclude that women with the DNMT1 SNP (A201G, rs2228612) GG homozygous genotype (variant) have a lower risk of developing breast cancer compared to heterozygous or wildtype genotypes. To date, alterations within the DNMT1 gene have not been reported to be associated with cancer in the Caucasian population.

Keywords: DNMT, SNP, Breast cancer

\section{Background}

Breast cancer is the most frequent malignancy in women and it is also the leading cause of death among women aged 40 to 50 years. Numerous risk factors of breast cancer have been reported in the literature and the most

\footnotetext{
* Correspondence: mahlknecht@gmx.de

'Department of Internal Medicine, Division of Immunotherapy and Gene Therapy, José Carreras Research Center, Saarland University Medical Center, Homburg/Saar D-66421, Germany

${ }^{4}$ Department of Hematology/Oncology, St Lukas Clinic Solingen, Schwanenstrasse 132, Solingen D-42697, Germany

Full list of author information is available at the end of the article
}

relevant factors are geographical variations, lifestyle, age at the time of diagnosis, age at first pregnancy, age at menarche, age at menopause and family history. BRCA1 and $B R C A 2$ are genes associated with an increased risk of developing breast cancer. Inherited mutations in the p53 and PTEN genes have been observed in the context of familial syndromes, Li-Fraumeni syndrome and Cowden's disease, which imply an increased risk of developing breast cancer. However, we need to consider that both Li-Fraumeni syndrome and Cowden's disease are rare conditions [1]. Epigenetic events are important 
in the pathogenesis and progression of breast cancer [2]. Histone acetylation and/or methylation, as well as DNA methylation, are epigenetic alterations which are reversible. Histone modifications take place in eukaryotic cells, while DNA methylation takes place in both eukaryotic and prokaryotic cells. Both are relevant key elements within the transcriptional regulatory machinery [3]. The epigenetic modification of DNA methylation is typically mediated by DNA methyltransferases (DNMTs). In cancer cells, there is a variation in 5-methylcytosine $\left(\mathrm{m}^{5} \mathrm{C}\right)$ transmission along with global DNA hypomethylation [4]. However, promoter CpG islands are typically hypermethylated in many types of cancers, which can lead to transcriptional silencing of the corresponding genes [5,6]. Accordingly, the hypermethylation of gene promoters or a hypomethylation of various parts of the genome can contribute to the development of cellular malignancy or autoimmune disease [7].

DNA methylation plays an important role in the control of gene expression in mammalian cells [8]. In breast cancer, it has been shown that the methylation of promoter regions in tumor suppressor genes can provide a growth advantage to malignant cells. For example the hypermethylation of the CpG islands in the estrogen receptor (ER)-promoter leads to the loss of ER protein expression. Therefore, the tumor is no longer under estrogen control and this causes the growth of cancer [9]. Nevertheless, with regard to human breast cancer, little is known about the clinical and biological relevance of DNMTs.
To date, four mammalian DNMTs have been identified: DNMT1, DNMT2 (TRDMT1), DNMT3A and DNMT3B [10-12]. DNMT1 was the first methyltransferase to be found [13], and it is also the major and most well characterized DNMT [14]. DNMTs can be divided into two groups, which are responsible for de novo and the maintenance of methylation (Figure 1) [15]. DNMT1 associates with the DNA replication fork and binds methyl groups to hemimethylated DNA during replication for the maintenance of methylation in the genome. The expression of DNMT1 is regulated by microRNAs (in breast cancer tissues microRNAs are globally downregulated) [16] and the methyltransferase activity is reduced by phosphorylation of DNMT1 [17]. Both mechanisms are involved in the regulation of global DNA methylation, but phosphorylation has been directly associated with tumorigenesis [17]. However, the precise role of DNMT1 functions in cancer cells is less well understood, since alterations of this gene have not been reported for cancer [18].

DNMT3A and DNMT3B are mainly involved in de novo methylation and they are important for the generation of methylation patterns during embryogenesis [19]. De novo DNMTs methylate cytosine to $\mathrm{m}^{5} \mathrm{C}$ postreplicatively from unmethylated DNA [3]. DNMT3A is also able to methylate cytosine within $\mathrm{CpA}$ and $\mathrm{CpT}$ dinucleotides, although this enzyme is highly specific for CpG methylation. However, the function of this DNA modification is still unknown [20]. The two functionally different groups of DNMTs may also interact with each

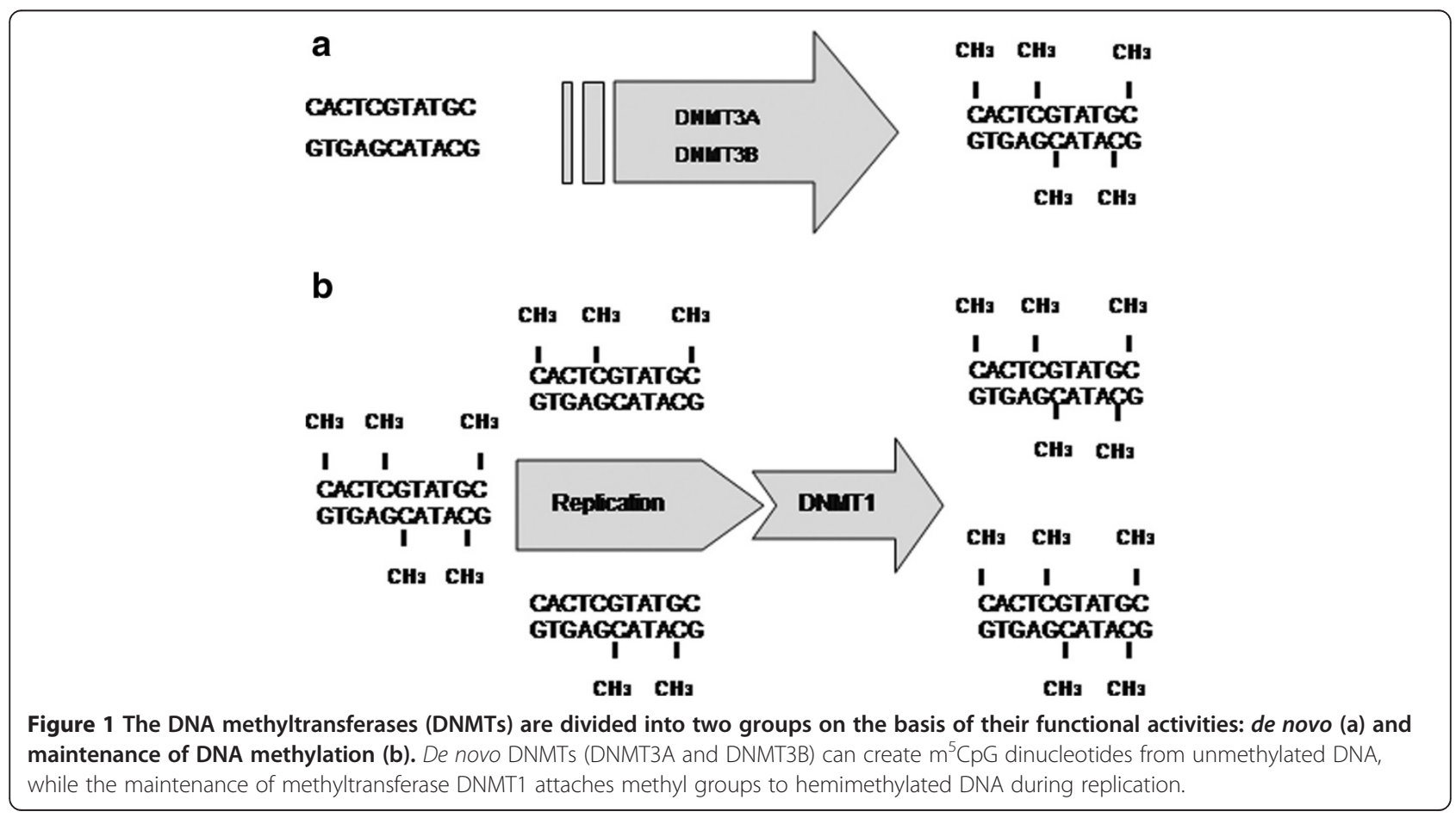


other and activate HDAC1, a histone deacetylase, which represses gene expression through the deacetylation of histone proteins, and thus a conformational change of the chromatin architecture [3]. DNMT2 (TRDMT1) is not only found in humans, but it is also found in other mammalian and non-mammalian species, and exhibits functional activities that are distinct from the other DNMTs. DNMT2 is an active RNA methyltransferase which is responsible for the methylation of the tRNA ${ }^{\text {Asp }}$ cytosine in position 38 (C38) [21]. It is the first example of an RNA methyltransferase to take advantage of the catalytic mechanisms of DNMT [22].

In order to assess the relevance of DNMT1, DNMT3A and DNMT3B SNPs on DNMT gene expression and associated enzymatic activities, a number of gene loci were identified in silico on the basis of the information obtained from literature and SNP databases: DNMT1 SNP (A201G, rs2228612), DNMT3A SNPs (G301C, rs34843713 and G301A, rs34191084) and DNMT3B SNPs (C501T, rs406193 and G301A, rs35846833). In this context, the DNMT2 (TRDMT1) gene has not been considered, because human DNMT2 is an RNA methyltransferase and this study was primarily focused on genes coding for DNMTs, and because they have been reported to play an important role in the development of cancer [3].

With the study presented herein, it was our intention to assess whether there was a correlation between DNMT SNPs and the risk of developing breast cancer.

\section{Case description}

Blood and peripheral blood mononuclear cell (PBMC) samples

In this study, we analyzed 221 DNA samples isolated from PBMCs of female Caucasian breast cancer patients and 221 DNA samples from female Caucasian healthy donors. Patient samples were collected at the Department of Obstetrics and Gynecology, Saarland University Medical Center, Germany, between 2001 and 2010. Control samples from healthy donors were collected at the Central Laboratory, University of Heidelberg Medical Center, Germany. All patients in the control group were below the age of 30 years. Genomic DNA was isolated from PBMCs and whole blood samples using the NucleoSpin Blood kit (Macherey-Nagel, Düren, Germany), in accordance with the manufacturer's instructions. Analyses of DNA purity and quantification were performed using a NanoDrop spectrophotometer (Thermo Scientific, Waltham, MA, USA).

\section{SNP selection}

We identified SNPs within the coding and promoter regions of the DNMT1, DNMT3A and DNMT3B genes via in silico analyses using data from the National Center for Biotechnology Information (NCBI, Bethesda, MD, USA), Applied Biosystems (Life Technologies, Carlsbad, CA, USA), GeneCards and HapMap. These SNPs carried the potential to affect the qualitative and quantitative expression of the DNMTs mentioned, and to search for potential associations with clinical parameters of breast cancer patients (Additional file 1 and Table 1). Five genomic loci corresponded to the criteria mentioned, and were further analyzed in the group of female Caucasian breast cancer patients and controls: DNMT1 SNP (A201G, rs2228612), DNMT3A SNPs (G301C, rs34843713 and G301A, rs34191084) and DNMT3B SNPs (C501T, rs406193 and G301A, rs35846833). DNMT3B SNP (C501T, rs406193) was selected on the basis of the publication by Cebrian et al. [2], which showed a reduced risk of breast cancer for the $\mathrm{T}$ allele (variant) within the DNMT3B gene. The DNMT1 SNP (A201G, rs2228612) was recently analyzed in Chinese women by Sun et al. [23] and they were able to demonstrate breast cancer susceptibility in women with the GG homozygote genotype (variant) [23]. The other SNPs were selected on the basis of non-synonymous SNPs, which could impact gene expression and/or protein function, because they lead to a modified amino acid product.

\section{Genotyping}

All samples of the selected tag SNPs were genotyped by real-time polymerase chain reaction (qPCR) or on TaqMan probes (Applied Biosystems, Darmstadt, Germany). qPCRs were carried out on $10 \mathrm{ng}$ of genomic DNA using TaqMan universal PCR Master Mix (Applied Biosystems, Darmstadt, Germany). Forward and reverse primers were labeled VIC and FAM (designed by Applied Biosystems) in a $5 \mu \mathrm{l}$ reaction (Table 2). The amplification conditions of TaqMan were as follows: 5 seconds at $50^{\circ} \mathrm{C}$, followed by 10 minutes at $95^{\circ} \mathrm{C}$ and 12 seconds at $92^{\circ} \mathrm{C}$, and finally 1 minute at $60^{\circ} \mathrm{C}$. A total of 40 cycles were run and the completed PCRs were then read in the end-point mode using the Allelic Discrimination Sequence Detector Software (Applied Biosystems). A total of 221 DNA samples from female Caucasian breast cancer patients and 221 DNA samples from female Caucasian healthy controls were assessed (Table 3).

\section{Statistical methods}

The Hardy-Weinberg equilibrium was tested using the Simple Hardy-Weinberg Calculator by Michael H Court (http://www.tufts.edu/ mcourt01/Documents/Court\% 20lab\%20-\%20HW\%20calculator.xls), by comparing the observed and expected genotype frequencies for cases and controls. Genotyping data generated for patients and controls were correlated with clinical parameters (age, diagnosis, histology, TNM status, ER status, 
Table 1 Distribution of the clinical parameters

\begin{tabular}{|c|c|c|}
\hline Clinical parameters & & $\begin{array}{l}\text { Distribution } \\
\text { (\%) }\end{array}$ \\
\hline \multirow[t]{3}{*}{ Age (years) } & 20 to 40 & 2.30 \\
\hline & 41 to 60 & 31.70 \\
\hline & 61 to $>80$ & 66.10 \\
\hline \multirow[t]{3}{*}{ Breast cancer diagnosis } & Right breast & 47.10 \\
\hline & Left breast & 46.10 \\
\hline & Both & 6.80 \\
\hline \multirow[t]{5}{*}{ Histology } & Ductal & 67.40 \\
\hline & Lobular & 15.40 \\
\hline & DCIS & 6.40 \\
\hline & LCIS & 1.80 \\
\hline & $\begin{array}{l}\text { Mixed and other tumor } \\
\text { types }\end{array}$ & 9.00 \\
\hline \multirow[t]{7}{*}{ TNM stage } & 1 & 36.70 \\
\hline & Ila & 24.40 \\
\hline & $\| b$ & 10.90 \\
\hline & IIla & 8.60 \\
\hline & $\| l l b$ & 5.00 \\
\hline & IIIC & 8.10 \\
\hline & IV & 6.30 \\
\hline \multirow[t]{2}{*}{ ER status } & Positive & 82.40 \\
\hline & Negative & 17.60 \\
\hline \multirow[t]{2}{*}{ PR status } & Positive & 72.40 \\
\hline & Negative & 27.60 \\
\hline \multirow[t]{3}{*}{ HER2 status } & Positive & 14.00 \\
\hline & Negative & 67.00 \\
\hline & Not defined & 19.00 \\
\hline \multirow{5}{*}{$\begin{array}{l}\text { Response of } \\
\text { chemotherapy }\end{array}$} & No chemotherapy/data & 48.00 \\
\hline & Complete remission & 32.10 \\
\hline & Recurrence & 5.90 \\
\hline & Stable disease & 8.10 \\
\hline & Progress & 5.90 \\
\hline \multirow[t]{3}{*}{ Survival } & Not detected & 10.90 \\
\hline & Alive & 76.00 \\
\hline & Death & 13.10 \\
\hline
\end{tabular}

DCIS, ductal carcinoma in situ; ER, estrogen receptor; HER2, human epidermal growth factor receptor 2; LCIS, lobular carcinoma in situ; PR, progesterone receptor; TNM, TNM Classification of Malignant Tumours.

progesterone receptor (PR) status, human epidermal growth factor receptor 2 (HER2) status, response to chemotherapy and survival) on the basis of the chisquared and Fisher's exact tests. $\mathrm{P}$ values $\leq 0.05$ were considered to be statistically significant. All analyses were performed using the statistical analysis software SPSS Statistics Version 17 for Windows (IBM, Armonk, NY, USA).
Body which gave approval: Ärztekammer des Saarlandes, Körperschaft des öffentlichen Rechts, Ethik-Kommission. Reference number: 192/09.

\section{Evaluation}

The correlation of the genotyping results with clinical parameters (age at the time of diagnosis, duration of disease, histology, TNM status, ER status, PR status, HER2 status, response of chemotherapy and survival) revealed no statistical significance. The correlation of the genotyping results between cases and controls showed no coherence for the DNMT3A SNPs (G301C, rs34843713 and G301A, rs34191084) and DNMT3B SNP (G301A, rs35846833). All women were homozygous for the DNMT3A GG and DNMT3B GG genotype. Based on information obtained from the NCBI database, the frequency of this polymorphism within the Caucasian population was reported to be $1.4 \%$ for the DNMT3A SNP (G301C, rs34843713) on the basis of 74 samples, $1.4 \%$ for the DNMT3B SNP (G301A, rs35846833) on the basis of 74 samples and $1.5 \%$ for the DNMT3A SNP (G301A, rs34191084) on the basis of 68 samples (Table 3).

The DNMT3B SNP (C501T, rs406193) was analyzed earlier as reported in the literature [2]. While Cebrian et al. showed that there was a significant difference in genotype distribution between breast cancer patients and controls, with the $\mathrm{T}$ allele (variant) associated with a reduced risk for breast cancer [2], our own analyses did not show a statistically significant correlation between the DNMT3B SNP and corresponding clinical parameters. Our genotyping data comparing patients and controls varied between $1.4 \%$ and $2.3 \%$ (Table 3), and were clearly lower than the frequencies reported in the NCBI database (12.5\% for DNMT3B SNP (C501T, rs406193) in central European Caucasian females) (Table 3). This analysis identified a statistical significance with a $P$ value of 0.05 .

We identified one additional statistically significant correlation for DNMT1 SNP (A201G, rs2228612), which appears to protect women against developing breast cancer.

The $P$ value of our results was 0.030 , in accordance with Fisher's exact test. The genotyping results showed that within the control group, 6 out of 221 women were GG homozygous (variant), while the homozygous variant genotype was not found in the group of breast cancer patients (Figure 2 and Table 3). Therefore, our results indicate that the $\mathrm{G}$ allele (variant) is associated with a reduced risk of developing breast cancer.

\section{Discussion}

In the case-control study presented herein, we correlated genetic polymorphisms in three genes, DNMT1, DNMT3A 
Table 2 Oligonucleotide primers

\begin{tabular}{|c|c|c|c|c|c|c|c|}
\hline rs number & Gene & SNP & AA & Position & Chromosome & Target sequence & Codon \\
\hline rs2228612 & DNMT1 & A201G & $\mathrm{I} / \mathrm{V}$ & Exon & 19 & 5'-CAGAAA(C/T)CTGTGG-3' & 327 \\
\hline rs34843713 & DNMT3A & G301C & $\mathrm{R} / \mathrm{P}$ & Exon & 2 & 5'-AAGGGG(C/G)GATCAT-3' & 749 \\
\hline rs34191084 & DNMT3A & G301A & $\mathrm{G} / \mathrm{S}$ & Exon & 2 & 5'-CATCGC(C/T)TGCTTT-3' & 278 \\
\hline rs406193 & DNMT3B & C501T & - & Intron & 20 & 5'-GAGACC(C/T)ATTAAT-3' & - \\
\hline rs35846833 & DNMT3B & G301A & $\mathrm{R} / \mathrm{C}$ & Exon & 20 & 5'-CGAAGA(C/T)GCACAG-3' & 320 \\
\hline
\end{tabular}

and $D N M T 3 B$, with clinical parameters to consider the risk of female Caucasians developing breast cancer.

The correlation with the SNPs in the DNMT genes and the clinical parameters showed no statistical significance. The identification of SNP alterations in association with other risk factors for breast cancer could provide an awareness of genetic variants that could lead to an increased susceptibility of breast cancer [24]. Milne et al. failed to identify conclusive associations between the 12 selected SNPs and the age at menarche, parity, age at first birth or body mass index (BMI) [24]. However, none of the DNMT SNPs tested in our study were considered in the study by Milne et al. [24]. Therefore, correlation of DNMT SNPs with clinical parameters and/or environmental risk factors such as breastfeeding, height, oral contraceptive and menopausal hormone therapy use, alcohol consumption, cigarette smoking and physical activity, could potentially yield significant insights of breast cancer risk, which may then be considered for the design of further studies in the future [25].

Two out of five SNPs in the DNMT1, DNMT3A and DNMT3B genes (DNMT3B SNP (C501T, rs406193) and DNMT1 SNP (A201G, rs2228612)) reached statistical significance $(\mathrm{P}=0.05$ and 0.03 , respectively). For DNMT3A, we assessed two SNPs (G301C, rs34843713 and G301A, rs34191084), which revealed the homozygous wildtype allele in all samples that were studied (cases and controls). DNMT3A SNPs with an impact on protein levels would have been of special interest, since Ley et al. showed that DNMT3A mutations are highly recurrent in patients with de novo acute myelogenous leukemia (AML) and with an intermediate-risk cytogenetic profile, and these patients also had a significantly reduced survival [26]. Furthermore, there is also a coherence between DNMT3A mutations and patients with myelodysplastic syndrome (MDS), since Walter et al. described the frequency of DNMT3A mutations in patients with de novo MDS and their association with secondary AML [27]. These mutations correlated with overall reduced survival and accelerated progression to AML [27]. AML and chronic myelogenous leukemia (CML) cells in the acute phase also showed increased expression levels for DNMT1, DNMT3A and DNMT3B when compared to normal bone marrow cells. However, such an over-expression of methyltransferases was not observed in the chronic phase in CML cells [28]. Since DNMT3B is able to mediate de novo DNA methylation and has been shown to be over-expressed in numerous types of cancer [14,28-31], this methyltransferase has been postulated to be an important factor in cancer, and it has been shown that DNMT3B polymorphisms are in fact significantly associated with the risk of developing lung cancer [32,33]. The level of DNMT3B protein is significantly elevated in hypermethylated human breast cancer cell lines, leading to an increased DNMT activity and high rates of methylation-dependent gene silencing

Table 3 Genotype distribution as listed in the NCBI database compared to data obtained in this study

\begin{tabular}{|c|c|c|c|c|c|c|c|c|}
\hline SNP & $\begin{array}{l}\text { Number of } \\
\text { samples } \\
\text { (NCBI data) }\end{array}$ & $\begin{array}{c}\text { Number of } \\
\text { samples } \\
\text { (study results) }\end{array}$ & $\begin{array}{l}\text { Wildtype } \\
\text { (NCBI data) }\end{array}$ & $\begin{array}{c}\text { Wildtype } \\
\text { (study results) }\end{array}$ & $\begin{array}{l}\text { Heterozygote } \\
\text { (NCBI data) }\end{array}$ & $\begin{array}{l}\text { Heterozygote } \\
\text { (study results) }\end{array}$ & $\begin{array}{c}\text { Variant } \\
\text { (NCBI data) }\end{array}$ & $\begin{array}{c}\text { Variant } \\
\text { (study results) }\end{array}$ \\
\hline DNMT1 SNP & 226 & $221^{a}$ & $88.50 \%$ & $87.3 \%^{\mathrm{a}}$ & $11.50 \%$ & $12.7 \%^{a}$ & $5.80 \%$ & $0 \%^{\mathrm{a}}$ \\
\hline (A201G, rs2228612) & & $221^{\mathrm{b}}$ & & $81.4 \%^{b}$ & & $15.8 \%^{\mathrm{b}}$ & & $2.7 \%^{\mathrm{b}}$ \\
\hline DNMT3A SNP & 74 & $221^{\mathrm{a}}$ & $97.30 \%$ & $100 \%^{\mathrm{a}}$ & $2.70 \%$ & $0 \%{ }^{\mathrm{a}}$ & $1.40 \%$ & $0 \%^{\mathrm{a}}$ \\
\hline (G301C, rs34843713) & & $221^{\mathrm{b}}$ & & $100 \%{ }^{b}$ & & $0 \%{ }^{\mathrm{b}}$ & & $0 \%^{\mathrm{b}}$ \\
\hline DNMT3A SNP & 68 & $221^{a}$ & $97.10 \%$ & $100 \%^{a}$ & $2.90 \%$ & $0 \%^{\mathrm{a}}$ & $1.50 \%$ & $0 \%^{\mathrm{a}}$ \\
\hline (G301A, rs34191084) & & $221^{\mathrm{b}}$ & & $100 \%^{\mathrm{b}}$ & & $0 \%^{\mathrm{b}}$ & & $0 \%^{\mathrm{b}}$ \\
\hline DNMT3B SNP & 120 & $221^{a}$ & $75 \%$ & $69.7 \%^{a}$ & $25 \%$ & $28 \%^{\mathrm{a}}$ & $12.50 \%$ & $2.3 \%^{\mathrm{a}}$ \\
\hline (C501T, rs406193) & & $221^{\mathrm{b}}$ & & $77.8 \%^{b}$ & & $20.8 \%^{b}$ & & $1.4 \%^{\mathrm{b}}$ \\
\hline DNMT3B SNP & 74 & $221^{\mathrm{a}}$ & $97.30 \%$ & $100 \%^{\mathrm{a}}$ & $2.70 \%$ & $0 \%^{\mathrm{a}}$ & $1.40 \%$ & $0 \%^{\mathrm{a}}$ \\
\hline (G301A, rs35846833) & & $221^{\mathrm{b}}$ & & $100 \%^{b}$ & & $0 \%^{\mathrm{b}}$ & & $0 \%^{\mathrm{b}}$ \\
\hline
\end{tabular}

${ }^{\mathrm{a}}$ Results of cases; ${ }^{\mathrm{b}}$ results of controls. NCBI, National Center for Biotechnology Information. 


\section{results of cases}
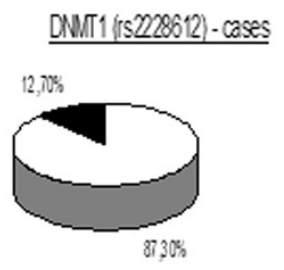

DNMT3B (rs406193) - cases

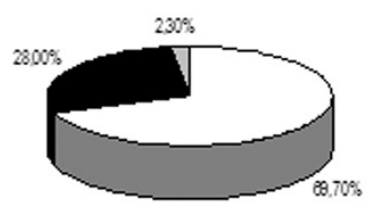

results of controls

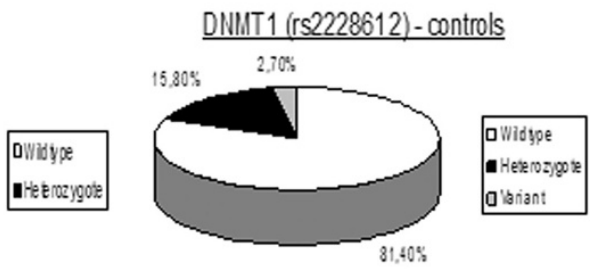

DNMT3B (rs406193) - controls

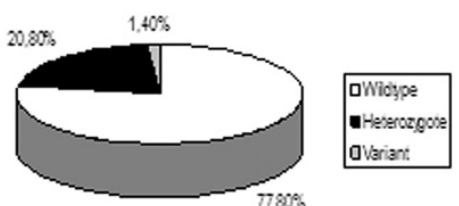

Figure 2 Genotyping results. In this study, we genotyped 221 female Caucasian breast cancer patients and 221 female Caucasian healthy controls. There was a statistical significance in the DNMT1 gene (DNMT1 SNP (A201G, rs2228612)) between cases and controls ( $P=0.03)$. The genotyping results in the DNMT3B gene (DNMT3B SNP (C501T, rs406193)) between cases and controls were also statistically significant $(P=0.05)$.

[31]. This is in accordance with other studies, which revealed an association of over-expressed DNMT3B levels and the development of breast cancer [8] and other malignancies [14,28-31].

In this study, we assessed two interesting DNMT3B SNPs, of which DNMT3B SNP (G301A, rs35846833) failed to be confirmed in the female Caucasian population, showing only the wildtype genotype in all samples. DNMT3B SNP (C501T, rs406193) showed a significant difference among cases and controls $(P$ value $=0.05)$ with the $\mathrm{T}$ allele (variant) associated with a reduced risk of developing breast cancer, while the statistical analysis of the correlation with clinical parameters was not significant. Montgomery et al. described a strong association between the $\mathrm{C}$ allele of the DNMT3B promoter polymorphism (C-149 T, rs2424913) and the risk of developing breast cancer, compared to TT homozygotes [34].

Ye et al. genotyped a total of 47 SNPs in the DNMT1 and DNMT3B genes, and the DNMT3B SNP (C501T, rs406193), which was also analyzed in our study [35]. Twenty-two of these SNPs, including the DNMT3B SNP (C501T, rs406193), were rejected from the analysis because either the minor allele frequencies were less than 0.005 in the study population or they were found to deviate from the Hardy-Weinberg equilibrium in controls. Thirteen SNPs in the DNMT3B gene (rs6058869, rs242908, rs6119954, rs6141813, rs4911108, rs4911259, rs910084, rs6088008, rs998382, rs4911110, rs6058893, rs6058896, rs8118663) were included in the analysis, but Ye et al. observed no association between these SNPs and breast cancer among Chinese women [35], which was inconsistent with the result of Cebrian et al. [2]. Cebrian et al. [2] showed statistical significance for
DNMT3B SNP (C501T, rs406193) (odds ratio (OR) CT versus $\mathrm{CC}=0.85$ (0.77 to 0.94$)$; $\mathrm{OR} \mathrm{TT}$ versus $\mathrm{CC}=$ 0.89 (0.64 to 1.23 ); $\mathrm{P}$ heterogeneity $=0.007 ; P$ trend $=$ $0.003)$. This association was in accordance with our statistical analysis, but Ye et al. could not confirm an apparent association of the DNMT3B polymorphism (C501T, rs406193) with the risk of breast cancer among Chinese women, since this SNP was found to have a minor allele frequency of less than 0.05 in the study population and was excluded from the analysis [35]. Consequently, we suggest that the mutation in the DNMT3B gene (C501T, rs406193) is only relevant in the female Caucasian population and not among the female Chinese population, which might be due to the difference of the allele frequency of this mutation between Caucasian (12.5\%) and Chinese patients (1.2\%), according to the NCBI database (since genetic mutations often vary between ethnic groups).

DNMT1 is a maintenance methyltransferase which attaches methyl groups to hemimethylated DNA during replication. To date, no genetic polymorphisms have been reported for DNMT1 in association with breast cancer in the female Caucasian population [18]. In the study presented herein, we identified one DNMT1 SNP (A201G, rs2228612) which could be relevant as a risk of developing breast cancer in the female Caucasian population. In relation to breast cancer risk, DNMT1 gene polymorphisms have been solely reported in association with sporadic infiltrating ductal breast cancer among Chinese women [36]. Xiang et al. studied two SNPs in the DNMT1 gene (T251C, rs16999593 and G301A, rs2228611), and reported significance between the SNPs and the PR and p53 status (p53-positive disease) [36]. Ye et al. analyzed 12 SNPs in the DNMT1 gene (rs2116940, 
rs2336691, rs7253062, rs16999593, rs6511685, rs6511 677, rs8101866, rs2241531, rs10418707, rs10407514, rs4804122, rs11085587), but they did not find any apparent association of DNMT1 mutation with the risk of breast cancer among Chinese women [35]. A recent article by Sun et al. found evidence of an association of breast cancer risk among Chinese Han women from South China with SNPs in the DNMT1 gene [23]. For DNMT1 SNP rs2228612, the frequency of the GG genotype (variant) of rs2228612 was higher in cases compared to controls (22.5\% versus $14.5 \%$ ) (OR AG versus $\mathrm{GG}=$ 1.71 (1.06 to 2.78); OR GG versus AA 1.75 (1.13 to 2.72); $P$ heterogeneity $=0.044 ; P$ trend $=0.013)$ [23]. These results contradict our own observations, which imply ethnic differences still remain to be further elucidated.

In this study, we were able to show a significant association between the DNMT1 gene polymorphism (A201G, rs2228612) and the risk of breast cancer in the female Caucasian population. The correlation of cases and controls showed a statistical significance with a $\mathrm{P}$ value of 0.030 (Fisher's exact test), whereas the statistical analyses of frequency differences between cases and clinical parameters revealed no significant results. While six female controls were GG homozygous (variant), there were no females in the group of breast cancer patients with the GG homozygous genotype (variant). Therefore, our results show that the DNMT1 gene polymorphism (A201G, rs2228612) with the g-allele (variant) is associated with a reduced risk of developing breast cancer.

\section{Conclusion}

In conclusion, our results showed that the two DNMT $3 A$ SNPs (G301C, rs34843713 and G301A, rs34191084) and the DNMT3B SNP (G301A, rs35846833) do not exist in the female Caucasian population. Otherwise, we could demonstrate a statistical significance in the differences of allele frequencies of cases and controls of the DNMT3B SNP (C501T, rs406193), like in the study of Cebrian et al. [2].

Finally, we identified a significant association of the DNMT1 SNP (A201G, rs2228612) variant in the correlation of cases and controls. Women with the $\mathrm{G}$ allele (variant) show a lower risk of developing breast cancer. The diagnostic impact of this new marker needs to be validated in further clinical studies in larger populations and within different ethnic groups, but it presents a further step towards a more individualized diagnosis.

\section{Additional file}

Additional file 1: Table S1. Data of breast cancer patients. Table S2. Explanation of the clinical parameters. The age of the patients are defined as age at the time of recruitment.

\section{Abbreviations}

AML: Acute myelogenous leukemia; BMI: Body mass index; C: Cytosine; CML: Chronic myelogenous leukemia; DNMT: DNA methyltransferase; ER: Estrogen receptor; HER2: Human epidermal growth factor receptor 2; m5C: 5-methylcytosine; MDS: Myelodysplastic syndrome; NCBI: National Center for Biotechnology Information; OR: Odds ratio; PBMC: Peripheral blood mononuclear cell; PR: Progesterone receptor; qPCR: Real-time polymerase chain reaction; SNP: Single nucleotide polymorphism; TNM: TNM Classification of Malignant Tumours.

\section{Competing interest}

All authors declare that they have no conflict of interest in association with this study.

\section{Authors' contributions}

KK carried out the molecular genetic studies and performed the statistical analysis with MFO. UM planned the study. KK and UM worked on the manuscript. All authors read and approved the final manuscript.

\section{Author details}

${ }^{1}$ Department of Internal Medicine, Division of Immunotherapy and Gene Therapy, José Carreras Research Center, Saarland University Medical Center, Homburg/Saar D-66421, Germany. ${ }^{2}$ Department of Obstetrics and Gynecology, Saarland University Medical Center, Homburg/Saar D-66421, Germany. ${ }^{3}$ Institute of Medical Biometrics, Epidemiology and Medical Informatics, Saarland University, Homburg/Saar D-66421, Germany. ${ }^{4}$ Department of Hematology/Oncology, St Lukas Clinic Solingen, Schwanenstrasse 132, Solingen D-42697, Germany.

Received: 29 November 2012 Accepted: 16 April 2013 Published: 2 May 2013

\section{References}

1. MCPherson K, Steel CM, Dixon JM: ABC of breast diseases. Breast cancerepidemiology, risk factors, and genetics. BMJ 2000, 321(7261):624-628.

2. Cebrian A, Pharoah PD, Ahmed S, Ropero S, Fraga MF, Smith PL, Conroy D, Luben R, Perkins B, Easton DF, Dunning AM, Esteller M, Ponder BA: Genetic variants in epigenetic genes and breast cancer risk. Carcinogenesis 2006, 27(8):1661-1669.

3. Turek-Plewa J, Jagodzinski PP: The role of mammalian DNA methyltransferases in the regulation of gene expression. Cell Mol Biol Lett 2005, 10(4):631-647.

4. Ehrlich M: DNA methylation in cancer: too much, but also too little. Oncogene 2002, 21(35):5400-5413.

5. Ting AH, MCGarvey KM, Baylin SB: The cancer epigenome-components and functional correlates. Genes Dev 2006, 20(23):3215-3231.

6. Baylin SB, Belinsky SA, Herman JG: Aberrant methylation of gene promoters in cancer--concepts, misconcepts, and promise. J Nat/ Cancer Inst 2000, 92(18):1460-1461.

7. Das PM, Singal R: DNA methylation and cancer. J Clin Oncol 2004, 22(22):4632-4642.

8. Girault I, Tozlu S, Lidereau R, Bièche I: Expression analysis of DNA methyltransferases $1,3 \mathrm{~A}$, and $3 \mathrm{~B}$ in sporadic breast carcinomas. Clin Cancer Res 2003, 9(12):4415-4422.

9. Giacinti L, Claudio PP, Lopez M, Giordano A: Epigenetic information and estrogen receptor alpha expression in breast cancer. Oncologist 2006, 11(1):1-8.

10. Yen RW, Vertino PM, Nelkin BD, Yu JJ, el-Deiry W, Cumaraswamy A, Lennon GG, Trask BJ, Celano P, Baylin SB: Isolation and characterization of the cDNA encoding human DNA methyltransferase. Nucleic Acids Res 1992, 20(9):2287-2291.

11. Bestor TH: The DNA methyltransferases of mammals. Hum Mol Genet 2000, 9(16):2395-2402.

12. Miremadi A, Oestergaard MZ, Pharoah PD, Caldas C: Cancer genetics of epigenetic genes. Hum Mol Genet 2007, 16(Spec No 1):R28-R49.

13. Bestor T, Laudano A, Mattaliano R, Ingram V: Cloning and sequencing of a cDNA encoding DNA methyltransferase of mouse cells. The carboxylterminal domain of the mammalian enzymes is related to bacterial restriction methyltransferases. J Mol Biol 1988, 203(4):971-983.

14. Saito $Y$, Kanai $Y$, Nakagawa T, Sakamoto M, Saito H, Ishii H, Hirohashi S: Increased protein expression of DNA methyltransferase (DNMT) 1 is 
significantly correlated with the malignant potential and poor prognosis of human hepatocellular carcinomas. Int J Cancer 2003, 105(4):527-532.

15. Robertson KD: DNA methylation, methyltransferases, and cancer. Oncogene 2001, 20(24):3139-3155.

16. Veeck J, Esteller M: Breast cancer epigenetics: from DNA methylation to microRNAs. J Mammary Gland Biol Neoplasia 2010, 15(1):5-17.

17. Lavoie G, Estève PO, Laulan NB, Pradhan S, St-Pierre Y: PKC isoforms interact with and phosphorylate DNMT1. BMC Biol 2011, 9(1):31.

18. Goll MG, Bestor TH: Eukaryotic cytosine methyltransferases. Annu Rev Biochem 2005, 74:481-514.

19. Bachman KE, Rountree MR, Baylin SB: Dnmt3a and Dnmt3b are transcriptional repressors that exhibit unique localization properties to heterochromatin. J Biol Chem 2001, 276(34):32282-32287.

20. Ramsahoye BH, Biniszkiewicz D, Lyko F, Clark V, Bird AP, Jaenisch R: Non-CpG methylation is prevalent in embryonic stem cells and may be mediated by DNA methyltransferase 3a. Proc Natl Acad Sci USA 2000, 97(10):5237-5242.

21. Goll MG, Kirpekar F, Maggert KA, Yoder JA, Hsieh CL, Zhang X, Golic KG, Jacobsen SE, Bestor TH: Methylation of tRNAAsp by the DNA methyltransferase homolog Dnmt2. Science 2006, 311(5759):395-398.

22. Jurkowski TP, Meusburger M, Phalke S, Helm M, Nellen W, Reuter G, Jeltsch A: Human DNMT2 methylates tRNA(Asp) molecules using a DNA methyltransferase-like catalytic mechanism. RNA 2008, 14(8):1663-1670.

23. Sun MY, Yang XX, Xu WW, Yao GY, Pan HZ, Li M: Association of DNMT1 and DNMT3B polymorphisms with breast cancer risk in Han Chinese women from South China. Genet Mol Res 2012, 11(4):4330-4341.

24. Milne RL, Gaudet MM, Spurdle AB, Fasching PA, Couch FJ, Benítez J, Arias Pérez Jl, Zamora MP, Malats N, Dos Santos SI, Gibson LJ, Fletcher O, Johnson N, Anton-Culver H, Ziogas A, Figueroa J, Brinton L, Sherman ME, Lissowska J, Hopper JL, Dite GS, Apicella C, Southey MC, Sigurdson AJ, Linet MS, Schonfeld SJ, Freedman DM, Mannermaa A, Kosma VM, Kataja V, et al: Assessing interactions between the associations of common genetic susceptibility variants, reproductive history and body mass index with breast cancer risk in the breast cancer association consortium: a combined case-control study. Breast Cancer Res 2010, 12(6):R110.

25. Nickels S, Truong T, Hein R, Stevens K, Buck K, Behrens S, Eilber U, Schmidt M, Häberle L, Vrieling A, Gaudet M, Figueroa J, Schoof N, Spurdle AB, Rudolph A, Fasching PA, Hopper JL, Makalic E, Schmidt DF, Southey MC, Beckmann MW, Ekici AB, Fletcher O, Gibson L, Dos Santos SI, Peto J, Humphreys MK, Wang J, Cordina-Duverger E, Menegaux F, et al: Evidence of gene-environment interactions between common breast cancer susceptibility loci and established environmental risk factors. PLOS Genet 2013, 9(3):e1003284.

26. Ley TJ, Ding L, Walter MJ, McLellan MD, Lamprecht T, Larson DE, Kandoth C, Payton JE, Baty J, Welch J, Harris CC, Lichti CF, Townsend RR, Fulton RS, Dooling DJ, Koboldt DC, Schmidt H, Zhang Q, Osborne JR, Lin L, O'Laughlin M, McMichael JF, Delehaunty KD, McGrath SD, Fulton LA, Magrini VJ, Vickery TL, Hundal J, Cook LL, Conyers JJ, et al: DNMT3A mutations in acute myeloid leukemia. N Engl J Med 2010, 363(25):2424-2433.

27. Walter MJ, Ding L, Shen D, Shao J, Grillot M, McLellan M, Fulton R, Schmidt H, Kalicki-Veizer J, O'Laughlin M, Kandoth C, Baty J, Westervelt P, DiPersio JF Mardis ER, Wilson RK, Ley TJ, Graubert TA: Recurrent DNMT3A mutations in patients with myelodysplastic syndromes. Leukemia 2011, 25(7):1153-1158.

28. Mizuno S, Chijiwa T, Okamura T, Akashi K, Fukumaki Y, Niho Y, Sasaki H: Expression of DNA methyltransferases DNMT1, 3A, and 3B in normal hematopoiesis and in acute and chronic myelogenous leukemia. Blood 2001, 97(5):1172-1179.

29. Robertson KD, Uzvolgyi E, Liang G, Talmadge C, Sumegi J, Gonzales FA, Jones PA: The human DNA methyltransferases (DNMTs) 1, 3a and 3b: coordinate mRNA expression in normal tissues and overexpression in tumors. Nucleic Acids Res 1999, 27(11):2291-2298.

30. Butcher DT, Rodenhiser DI: Epigenetic inactivation of BRCA1 is associated with aberrant expression of CTCF and DNA methyltransferase (DNMT3B) in some sporadic breast tumours. Eur J Cancer 2007, 43(1):210-219.

31. Roll JD, Rivenbark AG, Jones WD, Coleman WB: DNMT3b overexpression contributes to a hypermethylator phenotype in human breast cancer cell lines. Mol Cancer 2008, 7:15.

32. Shen $H$, Wang L, Spitz MR, Hong WK, Mao L, Wei Q: A novel polymorphism in human cytosine DNA-methyltransferase-3B promoter is associated with an increased risk of lung cancer. Cancer Res 2002, 62(17):4992-4995.
33. Lee SJ, Jeon HS, Jang JS, Park SH, Lee GY, Lee BH, Kim CH, Kang YM, Lee WK, Kam S, Park RW, Kim IS, Cho YL, Jung TH, Park JY: DNMT3B polymorphisms and risk of primary lung cancer. Carcinogenesis 2005, 26(2):403-409.

34. Montgomery KG, Liu MC, Eccles DM, Campbell IG: The DNMT3B C->T promoter polymorphism and risk of breast cancer in a British population: a case-control study. Breast Cancer Res 2004, 6(4):R390-R394

35. Ye C, Beeghly-Fadiel A, Lu W, Long J, Shu XO, Gao YT, Zheng W, Cai Q: Two-stage case-control study of DNMT-1 and DNMT-3B gene variants and breast cancer risk. Breast Cancer Res Treat 2010, 121(3):765-769.

36. Xiang G, Zhenkun F, Shuang $C$, Jie Z, Hua Z, Wei J, Da P, Dianjun L: Association of DNMT1 gene polymorphisms in exons with sporadic infiltrating ductal breast carcinoma among Chinese Han women in the Heilongjiang Province. Clin Breast Cancer 2010, 10(5):373-377.

doi:10.1186/1868-7083-5-7

Cite this article as: Kullmann et al:: DNMT1 genetic polymorphisms affect breast cancer risk in the central European Caucasian population. Clinical Epigenetics 2013 5:7.

\section{Submit your next manuscript to BioMed Central and take full advantage of:}

- Convenient online submission

- Thorough peer review

- No space constraints or color figure charges

- Immediate publication on acceptance

- Inclusion in PubMed, CAS, Scopus and Google Scholar

- Research which is freely available for redistribution 